\title{
The ESHRE-ESGE consensus on the classification of female genital tract congenital anomalies
}

\author{
Grigoris F. Grimbizis • Stephan Gordts • Attilio Di Spiezio Sardo • \\ Sara Brucker • Carlo De Angelis • Marco Gergolet • Tin-Chiu Li • \\ Vasilios Tanos • Hans Brölmann • Luca Gianaroli • Rudi Campo
}

Received: 14 March 2013 / Accepted: 8 April 2013 /Published online: 13 June 2013

(C) The Author(s) 2013. This article is published with open access at Springerlink.com

\begin{abstract}
The new ESHRE/ESGE classification system of female genital anomalies is presented, aiming to provide a more suitable classification system for the accurate, clear, correlated with clinical management and simple categorization of female genital anomalies. Congenital malformations of the female genital tract are common miscellaneous deviations from normal anatomy with health and reproductive consequences. Until now, three systems have been proposed for their categorization, but all of them are associated with serious limitations. The European Society of Human Reproduction and Embryology (ESHRE) and the European Society for Gynaecological Endoscopy (ESGE) have established a common Working Group, under the name CONUTA (CONgenital UTerine Anomalies), with the goal of developing a new updated classification system. A scientific committee has been appointed to run the project, looking also for consensus within the scientists working in the field. The new system is designed and developed based on: (1) scientific research through critical review of current proposals
\end{abstract}

ESHRE pages content is not externally peer-reviewed. The manuscript has been approved by the Executive committee of ESHRE.

This manuscript is being published simultaneously in the journals of Human Reproduction and Gynecological Surgery.

G. F. Grimbizis · S. Gordts · A. Di Spiezio Sardo $\cdot$ S. Brucker $\cdot$

C. De Angelis $\cdot$ M. Gergolet $\cdot$ T.-C. Li $\cdot$ V. Tanos $\cdot$ H. Brölmann •

L. Gianaroli $\cdot$ R. Campo

Congenital Uterine Anomalies (CONUTA) common ESHRE-ESGE

Working Group, ESGE Central Office, Diestsevest 43/0001,

3000, Leuven, Belgium

G. F. Grimbizis $(\bowtie)$

First Department of Obstetrics \& Gynecology,

Aristotle University of Thessaloniki, Tsimiski 51 Street,

54623, Thessaloniki, Greece

e-mail: grimbi@med.auth.gr

G. F. Grimbizis

e-mail: grigoris.grimbizis@gmail.com and preparation of an initial proposal for discussion between the experts, (2) consensus measurement among the experts through the use of the DELPHI procedure and (3) consensus development by the scientific committee, taking into account the results of the DELPHI procedure and the comments of the experts. Almost 90 participants took part in the process of development of the ESHRE/ESGE classification system, contributing with their structured answers and comments. The ESHRE/ESGE classification system is based on anatomy. Anomalies are classified into the following main classes, expressing uterine anatomical deviations deriving from the same embryological origin: U0, normal uterus; U1, dysmorphic uterus; $U 2$, septate uterus; U3, bicorporeal uterus; U4, hemi-uterus; U5, aplastic uterus; U6, for still unclassified cases. Main classes have been divided into sub-classes expressing anatomical varieties with clinical significance. Cervical and vaginal anomalies are classified independently into sub-classes having clinical significance. The ESHRE/ESGE classification of female genital anomalies seems to fulfil the expectations and the needs of the experts in the field, but its clinical value needs to be proved in everyday practice. The ESHRE/ESGE classification system of female genital anomalies could be used as a starting point for the development of guidelines for their diagnosis and treatment.

Keywords ESHRE $\cdot$ ESGE $\cdot$ Female genital tract congenital anomalies $\cdot$ ESHRE/ESGE classification system .

DELPHI procedure

\section{Introduction}

Congenital malformations of the female genital tract are defined as deviations from normal anatomy resulting from embryological maldevelopment of the Müllerian or paramesonephric ducts. They represent a rather common benign condition with a prevalence of 4 to $7 \%[7,13,26]$. 
Moreover, depending on the type and the degree of anatomical distortion, they are associated with health and reproductive problems [5, 8, 10, 12, 13, 16, 18, 20, 25, 27]. Due to their prevalence and clinical importance, a reliable classification system seems to be extremely useful for their management; effective categorization enables more effective diagnosis and treatment as well as a better understanding of their pathogenesis [14].

Until now, three systems have been proposed for the classification of female genital tract anomalies, although historically attempts for their categorization started quite earlier [2, 14]: the American Fertility Society's (AFS) currently American Society of Reproductive Medicine system $[3,6]$, the embryological-clinical classification system of genito-urinary malformations $[1,2]$ and the Vagina, Cervix, Uterus, Adnexae and associated Malformations system based on the Tumor, Nodes, Metastases principle in oncology [21].

Although each proposal does not have the same acceptance, with that of the AFS classification system to be higher than the others, all of them seem to be associated with serious limitations in terms of effective categorization of the anomalies, clinical usefulness, simplicity and friendliness [14]. It is noteworthy to mention that these limitations also originated further subdivisions for certain categories of anomalies $[9,17$, $18,24,25,27,30]$. A systematic re-evaluation of the current proposals, within a project of the European Academy for Gynecological Surgery (EAGS), has been already published underlying the need for a new and updated clinical classification system [14].

The European Society of Human Reproduction and Embryology (ESHRE) and the European Society for Gynaecological Endoscopy (ESGE), recognizing the clinical significance of female genital anomalies, have established a common working group under the name CONUTA (CONgenital UTerine Anomalies), with the goal of developing a new updated classification system. For this purpose, a scientific committee has been appointed to run the project, looking also for consensus within the scientists working in the field through the use of DELPHI procedure [11, 14, 19].

The ESHRE/ESGE classification system of female genital anomalies is presented in this paper. It is designed having mainly clinical orientation and being based on the anatomy of the female genital tract.

\section{Strategy for the development of the new system}

The development of the new ESHRE/ESGE classification system by the CONUTA ESHRE/ESGE Working group included the following steps (Fig. 1): (1) scientific work for the preparation of the questionnaires, the design of the new system and the preparation of an initial proposal for discussion among the experts in the field, (2) consensus measurement through the use of the DELPHI procedure to assess the extent of agreement of the experts and to have their comments for the development of the new system and (3) consensus development through the incorporation of the results of the DELPHI procedure and of the comments of the experts by the scientific committee into the final classification system.

Scientific work for the design of the new system

Scientific work was necessary for the evidence-based development of the new classification system; it was also a prerequisite for the design of the structured questionnaires for the DELPHI procedure.

The scientific work had two distinct parts; (1) As first part, a systematic re-evaluation of the current proposals has been done and, based on their criticism, the characteristics of the new classification system have been clarified [14]. This work was run as a project of the EAGS, and it was later adopted by the Scientific Committee of the CONUTA group. This document has been used as the scientific basis for the design of the structured questionnaire for the DELPHI procedure. (2) The second part was the preparation of a proposal for the new updated clinical classification of female genital anomalies to be used during the DELPHI procedure to rank the agreement of the experts and to have their comments before deciding the final classification system. The proposal of the SC for the classification of uterine anomalies has only been published just before the second round of the DELPHI procedure [15] in order to have the blind answers of the experts during round one.

\section{DELPHI procedure for consensus assessment}

DELPHI procedure is a well-known consensus method enabling to derive quantitative estimates through qualitative approaches. It aims to rank the agreement on a scientific issue with conflicting evidence, the extent to which each participant agrees with the issue under consideration and the extent to which the responders agree with each other [11, 19, 31].

The DEPLHI procedure for the development of the new classification system has been designed and processed into two rounds as follows:

\section{Preparation phase}

1. Preparation of the structured questionnaires

The SC, based on the scientific work previously described, has designed for the first round of the DELPHI procedure a structured questionnaire aiming to have the opinion of the participants on the need and the desired characteristics of a new classification system. For this 


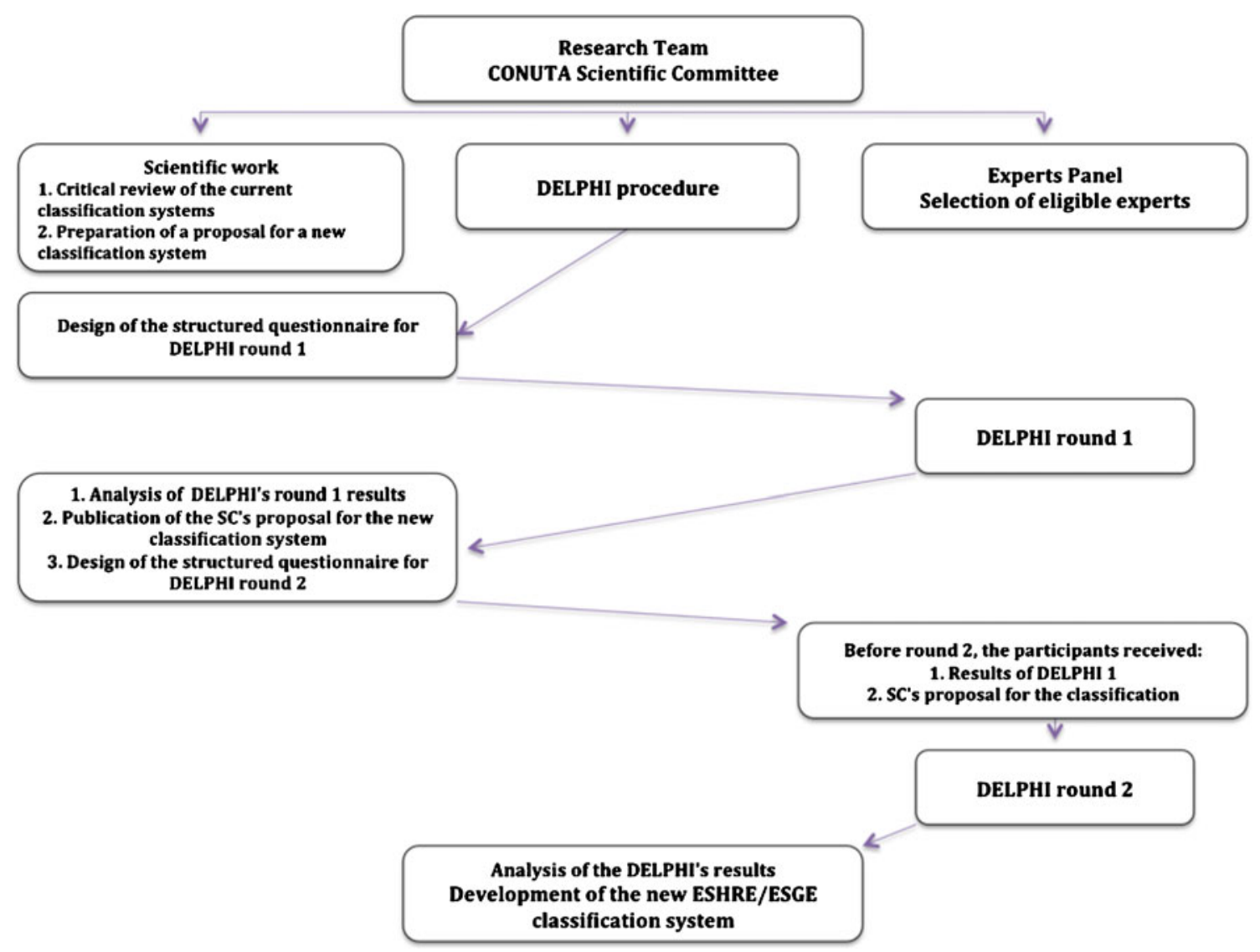

Fig. 1 Design and running of the project; the stepwise Delphi consensus method has been used to find the agreement between the experts in the development of the new classification system

reason, questions have been grouped under a limited number of headings and statements drafted for circulation to all participants (Table 1). Furthermore, there was a section for comments. For the second round, the questionnaire has been changed aiming to assess the agreement of the participants with the new proposal and to have their comments on it (Table 2).

It should be noted that in the same questionnaire there were parts aiming to assess the opinion of the participants for the existing classification systems (their advantages and their limitations) and to have their comments on them; the results on this issue will be presented in another document.

The agreement rate for each statement was calculated as follows: no. of participants who agree-no. of participants who disagree/no. of participants (agree+indifferent + disagree); agreement rates $>67 \%$ are considered as consensus for agreement and $<-67 \%$ as consensus for disagreement among the participants. Values between 50 and $67 \%$ are considered as indication of acceptance, whereas between -50 and $-67 \%$ as indication of rejection of the statement considered. Any value between 50 and $-50 \%$ is considered as an expression of neutral opinion.
2. Selection of participants

The selection of participants in the DELPHI procedure was a crucial issue. The $\mathrm{SC}$ decided to remain within the European borders since it was a European project; an invitation to participate together with a selection questionnaire was sent to all members of the ESHRE SIG RS (Special Interest Group Reproductive Surgery), all the ESGE members and to selected wellknown European experts in the field. Acceptance of the invitation is thought to be an expressed interest in the field of female genital anomalies and responders were included in the list of the participants of the DELPHI procedure. In total, the invitation has been sent to 454 professionals; 118 of them responded, thus becoming the participants of the DEPLHI procedure.

\section{DELPHI procedure round 1}

DELPHI questionnaire has been sent to the 118 experts who accepted to participate in the procedure; participants were asked to rank their agreement with each statement 
Table 1 The need for and the characteristics of a new classification system: structured questionnaire for the first round of the DELPHI procedure

I. Is there a need for a new classification system?

$\begin{array}{lllll}\text { Strongly agree } & \text { Agree } & \text { Indifferent } & \text { Disagree } & \text { Strongly disagree } \\ 42 / 89(47.2 \%) & 35 / 89(39.3 \%) & 8 / 89(9 \%) & 4 / 89(4.5 \%) & 0 \% \\ \text { Agreement: } 86.5 \%, & & 9 \% & \text { Disagreement: } 4.5 \%\end{array}$

Rate of agreement: $82 \%$

II. Select the three most important characteristics that should be taken into account in the development of a new system

$\begin{array}{lll}\text { Characteristic } & \text { Ranking } & \text { Selected as one of the three } \\ \text { Clear and accurate } & 1 s t & 72.1 \% \\ \text { Comprehensive } & & 36.8 \% \\ \text { Correlated with patient's clinical presentation } & & 39.7 \% \\ \text { Correlated with patient's management } & 2 n d & 66.2 \% \\ \text { Simple and friendly } & 3 r d & 64.7 \% \\ \text { Smooth movement from the old to } & & 20.6 \%\end{array}$

the new one

III. Which of the following statements should be taken into account in the development of a new system

1. Anatomy should be the basic characteristic for patients' grouping

$\begin{array}{lllll}\text { Strongly agree } & \text { Agree } & \text { Indifferent } & \text { Disagree } & \text { Strongly disagree } \\ 51 / 89(57.3 \%) & 33 / 89(37.1 \%) & 5 / 89(5.6 \%) & 0 \% & 0 \% \\ \text { Agreement: } 94,4 \%, & & 5.6 \% & \text { Disagreement: } 0 \% & \end{array}$

Rate of agreement: $94.4 \%$

2. There is a "key" organ of the female genital tract that should be used in priority for the development of a new system

\begin{tabular}{|c|c|c|c|c|}
\hline Strongly agree & Agree & Indifferent & Disagree & Strongly disagree \\
\hline $25 / 89(28.1 \%)$ & $30 / 89(33.7 \%)$ & $24 / 89(27.0 \%)$ & $9 / 89(10.1 \%)$ & $1 / 89(1.1 \%)$ \\
\hline Agreement: $61,8 \%$, & & $27.0 \%$ & Disagreement: & \\
\hline In case of agreement, indicate: & & Uterus & & \\
\hline
\end{tabular}

Rate of agreement: $50.6 \%$

3. Embryological origin should be the basic characteristic for patients' grouping

$\begin{array}{lllll}\text { Strongly agree } & \text { Agree } & \text { Indifferent } & \text { Disagree } & \text { Strongly disagree } \\ 12 / 89(13.5 \%) & 13 / 89(14.6 \%) & 42 / 89(47.2 \%) & 20 / 89(22.5 \%) & 2 / 89(2.2 \%) \\ \text { Agreement: } 28,1 \%, & & 47.2 \% & \text { Disagreement: } 24.7 \%\end{array}$

Rate of agreement: $3.4 \%$

4. Embryological origin should be used, if feasible, as a secondary characteristic for patients' grouping

$\begin{array}{lllll}\text { Strongly agree } & \text { Agree } & \text { Indifferent } & \text { Disagree } & \text { Strongly disagree } \\ 13 / 89(14.6 \%) & 50 / 89(56.2 \%) & 18 / 89(20.2 \%) & 7 / 89(7.9 \%) & 1 / 89(1.1 \%) \\ \text { Agreement: } 70.8 \%, & & 20.2 \% & \text { Disagreement: } 9.0 \%\end{array}$

Rate of agreement: $61.8 \%$

IV. Comments (feel free to make additional comments)

The scale of answers includes five degrees to rank the agreement in each scientific issue; the extent of agreement between the participants is shown in percentages

in the questionnaire and to add their comments at the end.

In total, $89(75.4 \%)$ participants responded to the questionnaire and made their comments. The main results of the first round were as follows (Table 1):

1. There was an agreement consensus among the participants that there was a need for a new classification system; agreement rate was as high as $82 \%$. This confirms the initial feeling of the scientific committee that the target to develop a new classification system corresponds to the needs of the scientific community.

2. Concerning the relative importance of the characteristics that a new system has to fulfill, the ranking was as follows (selected as one of the three more important characteristics): first to be clear and accurate with $72.1 \%$, second to be correlated with patient's management with $66.2 \%$ and third to be simple and user friendly with $64.7 \%$. The smooth transition from the old systems (mainly that of AFS) to the new one was the last in the ranking preferences of the participants. 
Table 2 Development of the new classification system; CONUTA proposal for the classification of female genital tract malformations; it has been sent to the participants together with the results of the first round just before the questionnaire of the second round

\begin{tabular}{|c|c|c|c|}
\hline & $\begin{array}{l}\text { Main class } \\
\text { Uterine anomaly }\end{array}$ & Main sub-class & $\begin{array}{l}\text { Co-existent sub-class } \\
\text { Cervical/vaginal } \\
\text { anomaly }\end{array}$ \\
\hline \multirow[t]{2}{*}{ Class 0} & \multirow[t]{2}{*}{ Normal uterus } & & Cervix \\
\hline & & & Co Normal \\
\hline \multirow[t]{2}{*}{ Class I } & \multirow[t]{2}{*}{ Dysmorphic uterus } & a. T-shaped & C1 Septate \\
\hline & & b. Infantilis & C2 Double "normal" \\
\hline \multirow[t]{2}{*}{ Class II } & \multirow[t]{2}{*}{ Septate uterus } & a. Partial & $\begin{array}{l}\text { C3 Unilateral aplasia / } \\
\text { dysplasia }\end{array}$ \\
\hline & & b. Complete & C4 Aplasialdysplasia \\
\hline \multirow[t]{2}{*}{ Class III } & \multirow{2}{*}{$\begin{array}{l}\text { Dysfused uterus } \\
\text { (including dysfused } \\
\text { "septate") }\end{array}$} & a. Partial & \\
\hline & & b. Complete & Vagina \\
\hline \multirow[t]{3}{*}{ Class IV } & \multirow[t]{3}{*}{ Unilaterally formed uterus } & \multirow{2}{*}{$\begin{array}{l}\text { a. Rudimentary horn with cavity } \\
\text { (communicating or not) }\end{array}$} & V0 Normal vagina \\
\hline & & & $\begin{array}{l}\text { V1 Longitudinal } \\
\text { non-obstructing } \\
\text { vaginal septum }\end{array}$ \\
\hline & & $\begin{array}{l}\text { b. Rudimentary horn without } \\
\text { cavity/aplasia (no horn) }\end{array}$ & $\begin{array}{l}\text { V2 Longitudinal obstructing } \\
\text { vaginal septum }\end{array}$ \\
\hline \multirow[t]{2}{*}{ Class V } & \multirow[t]{2}{*}{ Aplastic/dysplastic } & $\begin{array}{l}\text { a. Rudimentary horn with cavity } \\
\text { (bi- or unilateral) }\end{array}$ & $\begin{array}{l}\text { V3 Transverse vaginal } \\
\text { septum/imperforate } \\
\text { hymen }\end{array}$ \\
\hline & & $\begin{array}{l}\text { b. Rudimentary horn without cavity } \\
\text { (bi- or unilateral)/aplasia }\end{array}$ & V4 Vaginal aplasia \\
\hline Class VI & Unclassified malformations & & \\
\hline
\end{tabular}

3. Concerning the selection of the basic characteristics for patients' grouping in a new system, the results were as follows:

- There was a high agreement consensus among the participants that "anatomy should be used as the main characteristic" for the development of the new system with an agreement rate of $94.4 \%$,

- Participants did not support the use of embryology as the primary characteristic for patients' grouping with an agreement rate of $3.4 \%$, but it seems that they could accept its use as a secondary characteristic with an agreement rate of $61.8 \%$.

- There was an indication of agreement among the participants that there is a key organ for patients' grouping with an agreement rate of $50.6 \%$, and most of them reported that this is uterus.

Thus, the main conclusions from the first round of the DELPHI procedure were that there was a need for a new classification system, which had to be clear and accurate in its definitions, correlated with patients' management and as simple as possible. The smooth transition from the old system, mainly that of AFS, to the new one was not important in the design and the acceptance of the new system. Furthermore, anatomy should be used as the basic characteristic for patients grouping. The degree of consensus among the participants regarding these statements was thought to be extremely high. Moreover, there was an indication that the uterus could be used as the key organ in the design of system's categories and embryology could be used as a secondary characteristic for patients' grouping.

\section{DELPHI procedure round 2}

The results of the first round have been taken into account in the new proposal for the classification system prepared in the meantime. After its publication [15], the scientific committee decided to start the second round of the DELPHI procedure.

Before sending DELPHI questionnaire round 2, the SC has sent to the participants: (1) the results of the first round and (2) the SC's proposal for the classification of female genital malformations (Fig. 1); DELPHI questionnaire round 2 (Table 2) has been sent 1 month later.

The participants have been asked to rank their agreement with each statement of the questionnaire and to add their comments at the end taking into account the results of the first round and the new proposed classification system.

In total, $71(79.8 \%)$ participants responded. The main results of the second round were as follows (Table 3): 
Table 3 Structured questionnaire for the second round of the DELPHI procedure; the participants have been asked to adapt their responses taking into account the answers of the first round and the new proposal

I. This new classification system fulfill my needs and expectations

$\begin{array}{lllll}\text { Strongly agree } & \text { Agree } & \text { Indifferent } & \text { Disagree } & \text { Strongly disagree } \\ 22 / 71(31.0 \%) & 40 / 71(56.3 \%) & 7 / 71(9.9 \%) & 1 / 71(1.4 \%) & 1 / 71(1.4 \%) \\ \text { Agreement: } 87.3 \% & & 9.9 \% & \text { Disagreement: } 2.8 \% & \end{array}$

Rate of agreement: $84.5 \%$

II. Please points out how far the following characteristics are addressed by the new classification.

1. It is clear and accurate (in definitions)

$\begin{array}{lllll}\text { Strongly agree } & \text { Agree } & \text { Indifferent } & \text { Disagree } & \text { Strongly disagree } \\ 37 / 71(52.1 \%) & 31 / 71(43.7 \%) & 2 / 71(2.8 \%) & 1 / 71(1.4 \%) & 0 \% \\ \text { Agreement: } 95.8 \% & & 2.8 \% & \text { Disagreement: } 1.4 \% & \end{array}$

Rate of agreement: $94.4 \%$

2. It is comprehensive

$\begin{array}{lllll}\text { Strongly agree } & \text { Agree } & \text { Indifferent } & \text { Disagree } & \text { Strongly disagree } \\ 29 / 71(40.8 \%) & 38 / 71(53.6 \%) & 2 / 71(2.8 \%) & 2 / 71(2.8 \%) & 0 \% \\ \text { Agreement: } 94.4 \% & & 2.8 \% & \text { Disagreement: } 2.8 \% & \end{array}$

Rate of agreement: $91.6 \%$

3. It is correlated with patient's clinical presentation

$\begin{array}{lllll}\text { Strongly agree } & \text { Agree } & \text { Indifferent } & \text { Disagree } & \text { Strongly disagree } \\ 26 / 71(36.6 \%) & 39 / 71(55 \%) & 4 / 71(5.6 \%) & 2 / 71(2.8 \%) & 0 \% \\ \text { Agreement: } 91.6 \% & & 5.6 \% & \text { Disagreement: } 2.8 \% & \end{array}$

Rate of agreement: $88.8 \%$

4. It is correlated with patient's management

$\begin{array}{lllll}\text { Strongly agree } & \text { Agree } & \text { Indifferent } & \text { Disagree } & \text { Strongly disagree } \\ 25 / 71(35.2 \%) & 38 / 71(53.5 \%) & 7 / 71(9.9 \%) & 1 / 71(1.4 \%) & 0 \% \\ \text { Agreement: } 88.7 \% & & 9.9 \% & \text { Disagreement: } 1.4 \% & \end{array}$

Rate of agreement: $87.3 \%$

5. It is simple and users friendly

$\begin{array}{llll}\text { Strongly agree } & \text { Agree } & \text { Indifferent } & \text { Disagree } \\ 32 / 71(45.1 \%) & 27 / 71(38.0 \%) & 10 / 71(14.1 \%) & 2 / 71(2.8 \%) \\ \text { Agreement: } 83.1 \% & & 14.1 \% & \text { Disagreement: } 2.8 \%\end{array}$

Strongly disagree

$0 \%$

Rate of agreement: $80.3 \%$

6. There is a smooth movement from the old proposals to the this new one

$\begin{array}{lllll}\text { Strongly agree } & \text { Agree } & \text { Indifferent } & \text { Disagree } & \text { Strongly disagree } \\ 16 / 71(22.5 \%) & 38 / 71(53.5 \%) & 13 / 71(18.4 \%) & 4 / 71(5.6 \%) & 0 \% \\ \text { Agreement: } 76,0 \% & & 18.4 \% & \text { Disagreement: } 5.6 \% & \end{array}$

Rate of agreement: $70.4 \%$

III. Which of the following statements are accomplished by the new system

1. Anatomy is used correctly as the basic characteristic for patients' grouping
Strongly agree
Agree
Indifferent
Disagree
$0 \%$
Strongly disagree
35/71 (49.3\%)
36/71 (50.7\%)
$0 \%$
Disagreement: $0 \%$
$0 \%$
Agreement: $100.0 \%$,
$0 \%$
Rate of agreement: $100 \%$
2. Uterus as the "key" organ of the female genital tract is used correctly in priority for the development of a new system

$\begin{array}{lllll}\text { Strongly agree } & \text { Agree } & \text { Indifferent } & \text { Disagree } & \text { Strongly disagree } \\ 39 / 71(55.0 \%) & 29 / 71(40.8 \%) & 1 / 71(1.4 \%) & 1 / 71(1.4 \%) & 1 / 71(1.4 \%) \\ \text { Agreement: } 95.8 \% & & 1.4 \% & \text { Disagreement: } 2.8 \% & \end{array}$

Rate of agreement: $93 \%$ 
Table 3 (continued)

\begin{tabular}{|c|c|c|c|c|}
\hline Strongly agree & Agree & Indifferent & Disagree & Strongly disagree \\
\hline $18 / 71(25.4 \%)$ & $33 / 71(46.5 \%)$ & $17 / 71(23.9 \%)$ & $3 / 71(4.2 \%)$ & $0 \%$ \\
\hline Agreement: $71.9 \%$ & & $23.9 \%$ & Disagreement: $4.2 \%$ & \\
\hline \multicolumn{5}{|c|}{ Rate of agreement: $67.7 \%$} \\
\hline \multicolumn{5}{|c|}{ 4. Embryological origin is used successfully as a secondary characteristic for patients' grouping } \\
\hline Strongly agree & Agree & Indifferent & Disagree & Strongly disagree \\
\hline $12 / 71(16.9 \%)$ & $42 / 71(59.2 \%)$ & $14 / 71(19.7 \%)$ & $2 / 71(2.8 \%)$ & $1 / 71(1.4 \%)$ \\
\hline Agreement: $76.1 \%$ & & $19.7 \%$ & Disagreement: $4.2 \%$ & \\
\hline \multicolumn{5}{|c|}{ Rate of agreement: $71.9 \%$} \\
\hline \multicolumn{5}{|c|}{ 5. Uterine anomalies are classified successfully in the proposed $V$ classes } \\
\hline Strongly agree & Agree & Indifferent & Disagree & Strongly disagree \\
\hline $23 / 71(32.3 \%)$ & $39 / 71(55.0 \%)$ & $7 / 71(9.9 \%)$ & $1 / 71(1.4 \%)$ & $1 / 71(1.4 \%)$ \\
\hline Agreement: $87.3 \%$ & & $9.9 \%$ & Disagreement: $2.8 \%$ & \\
\hline
\end{tabular}

Rate of agreement: $84.5 \%$

6. The classification of fusion defects in one class (Dysfused uterus/Class III) instead of two in the AFS classification (Didelphys and Bicornuate uterus) system is more functional and helps in creating a more accurate and clear in definition category

$\begin{array}{lllll}\text { Strongly agree } & \text { Agree } & \text { Indifferent } & \text { Disagree } & \text { Strongly disagree } \\ 21 / 71(29.5 \%) & 33 / 71(46.5 \%) & 9 / 71(12.7 \%) & 8 / 71(11.3 \%) & 0 \% \\ \text { Agreement: } 76.0 \% & & 12.7 \% & \text { Disagreement: } 11.3 \% & \end{array}$

Agreement: $76.0 \%$

$12.7 \% \quad$ Disagreement: $11.3 \%$

Rate of agreement: $64.7 \%$

7. The addition of normal uterus as Class 0 gives the opportunity to effectively classify cervical and/or vaginal only anomalies and, thus, obstructive anomalies

$\begin{array}{lllll}\text { Strongly agree } & \text { Agree } & \text { Indifferent } & \text { Disagree } & \text { Strongly disagree } \\ 36 / 71(50.7 \%) & 26 / 71(36.6 \%) & 6 / 71(8.5 \%) & 3 / 71(4.2 \%) & 0 \% \\ \text { Agreement: } 87.3 \% & & 8.5 \% & \text { Disagreement: } 4.2 \% & \end{array}$

Rate of agreement: $83.1 \%$

8. The independent classification of cervical and vaginal anomalies gives the opportunity to clearly classify the female's genital tract anomalies

$\begin{array}{lllll}\text { Strongly agree } & \text { Agree } & \text { Indifferent } & \text { Disagree } & \text { Strongly disagree } \\ 32 / 71(45.1 \%) & 36 / 71(50.7 \%) & 2 / 71(2.8 \%) & 1 / 71(1.4 \%) & 0 \% \\ \text { Agreement: } 95.8 \% & & 2.8 \% & \text { Disagreement: } 1.4 \% & \end{array}$

Rate of agreement: $94.4 \%$

9. Cervical and vaginal anomalies are classified successfully in the proposed 4 classes

$\begin{array}{lllll}\text { Strongly agree } & \text { Agree } & \text { Indifferent } & \text { Disagree } & \text { Strongly disagree } \\ 20 / 71(28.1 \%) & 41 / 71(57.8 \%) & 8 / 71(11.3 \%) & 2 / 71(2.8 \%) & 0 \% \\ \text { Agreement: } 85.9 \% & & 11.3 \% & \text { Disagreement: } 2.8 \% & \end{array}$

Rate of agreement: $83.1 \%$

IVa. Could you please report a case that, according to you, could not be effectively classified by this new system?

IVb. Comments (feel free to make additional comments); please notice that it is important

The scale of answers includes five degrees to rank the agreement in each scientific issue; the extent of agreement between the participants is shown in percentages

1. There was an agreement consensus among the participants that the new system fulfills their needs and expectations with an agreement rate as high as $84.5 \%$,

2. More importantly, there was a high agreement consensus that the new proposed system seemed to be clear and accurate in its definitions with an agreement rate of $94.4 \%$, comprehensive with an agreement rate of $91.6 \%$, correlated with patients' clinical presentation with an agreement rate of $88.8 \%$ and correlated with patients' management with an agreement rate of $87.3 \%$. 
Furthermore, there was also an agreement consensus that the new system seemed to be simple and user friendly with an agreement rate of $80.3 \%$. Moreover, there was an agreement consensus that the new system gives the opportunity for a smooth transition from the old AFS system with an agreement rate of $70.4 \%$, although this was not ranked as being important during the DELPHI round 1.

3. The third part of the structured questionnaire included questions aiming to evaluate the agreement of participants on the design of the new system and the grouping of patients; the new system incorporates a lot of radical changes in the way of categorization. There was an absolute agreement consensus that "anatomy is used correctly as the basic characteristic in patients grouping" with $100 \%$ agreement rate, an extremely high agreement consensus that the "uterus is also correctly used as the key organ for the design of main classes" with an agreement rate of $93 \%$ and a high agreement consensus that "uterine anomalies are classified successfully in the proposed $\mathrm{V}$ classes" with an agreement rate of $84.5 \%$; the acceptance of these three points with such high rates is very important since they represent key concepts of the new system.

- There was an agreement consensus that "embryological origin is used successfully as a secondary characteristic for patients' grouping" with an agreement rate of $71.9 \%$.

- There was a high agreement consensus among the participants that the addition of normal uterus as class 0 gives the opportunity to effectively classify cervical and/or vaginal anomalies and, thus, obstructive anomalies" with an agreement rate of $83.1 \%$, an extremely high agreement consensus that "the independent classification of cervical and vaginal anomalies gives the opportunity to clearly classify female genital anomalies" with an agreement rate of $94.4 \%$ and a high agreement consensus that "cervical and vaginal anomalies are successfully classified in the proposed 4 classes" with an agreement rate of $83.1 \%$; acceptance of these concepts is also very important since they represent a radical change in the classification design of the new system.

- There was an indication of agreement (although not an agreement consensus) that "the classification of fusion defects in one class (Dysfused uterus/Class III) instead of two (Didelphys and Bicornuate uterus) in the AFS classification system is more functional and helps creating a more accurate and clear definition category" with an agreement rate of $64.7 \%$. This point was another change in the design of the new system; taking into account the results of the DELPHI procedure and some comments of the responders, the members of the SC focused on the need to further clarify the terminology, the clinical concept and the definitions of this class and its sub-classes.

- Furthermore, there were a lot of very useful comments from the participants, which were taken into account in the final version of the new system.

Thus, the main conclusion of the second round was that it was observed an agreement consensus among the participants for the new proposed system. However, there were some points that could be incorporated creatively in the classification of female genital anomalies.

\section{Consensus development}

The final step in the creation of the new classification system was the development of consensus. For this reason, the results of the DELPHI procedure and the comments of the participants have been critically evaluated, and the appropriate changes have been incorporated in the final version of the ESHRE/ESGE classification system. The main decisions of the SC in the process of consensus development were as follows:

- The results of the DELPHI procedure indicated that the proposal of the SC fulfilled the expectations of scientists and was accepted by them; hence, it was decided to keep the main concepts in the design and the classes of the new system.

- Together with the results of the DELPHI procedure for class III (dysfused uterus), indicating the need for further clarification of its concepts and definitions, there was a comment pointing out that the term "dysfused" is not commonly used. Examining this issue, the SC underlined that a descriptive term of the uterine gross morphology has been already adopted for most classes of the new system; on the contrary, the chosen term "dysfused" is mainly an embryological one creating confusion. Thus, it was decided to change this term with one describing the morphology of the uterus and including in its meaning the former "bicornuate" and "didelphys" uterus; the term bicorporeal is adopted as it was deemed more appropriate. Furthermore, in order to keep the same principles in the classes terminology, the term "unilaterally formed uterus" was changed to "Hemi-uterus".

- The "dysfused septate" uterus resulting from a concomitant fusion and absorption defect was included as a clear subcategory (IIIc) of class III as "bicorporeal septate uterus".

- The absence of arcuate uterus from the new classification system has been commented by a lot of participants; some groups supported the notion that even very small deformities of the uterine cavity (arcuate uterus) could be associated with poor pregnancy outcome [12, 29]. However, it was pointed out that until now the term 
arcuate was quite confusing including patients with different degrees of uterine deformity, even partial septa, since its definition is not clear at all. Hence, the necessity to have clear definitions was more than obvious based on the experience gained from the application of the AFS system. Thus, it was decided that septate uterus should remain a clear category including only patients with midline indentation of $>50 \%$ of the uterine wall thickness. A new subcategory under the general term "others" was added in class I/dysmorphic uterus, giving the opportunity to include all minor deformities of endometrial cavity including midline indentations less than $50 \%$ of the uterine wall thickness; the clinical value of this variant needs further clinical research. Thus, definition of classes and especially those of septate uterus remained clear.

- There were some comments regarding the subcategories of cervical and vaginal anomalies. A proposal to include partial vaginal agenesis as a different subcategory has not been adopted since it does not seem to be of any clinical value. The term (cervical/vaginal) dysplasia was deleted from the classification since it is generally used for intraepithelial neoplasia. Thus, the subcategories remained as in the initial proposal.

- The simplicity of the new system has been discussed. It was pointed out that for the vast majority of anomalies, only the use of uterine categories was necessary, while cervical and vaginal ones were not.

In conclusion, the ESHRE/ESGE classification system was the final result of a process including scientific research, consensus assessment and consensus development.

\section{The ESHRE/ESGE classification system}

Design of the new system: main concepts

The ESHRE/ESGE classification system is presented in Figs. 2 and 3. It has the following general characteristics:

1. Anatomy is the basis for the systematic categorization of anomalies

2. Deviations of uterine anatomy deriving from the same embryological origin is the basis for the design of the main classes

3. Anatomical variations of the main classes expressing different degrees of uterine deformity and being clinically significant are the basis for the design of the main sub-classes

4. Cervical and vaginal anomalies are classified in independent supplementary subclasses.

Anomalies are sorted in the classes and subclasses of the system according to increasing severity of the anatomical deviation; the less severe variants are placed in the beginning, the more deformed types at the end. For sake of simplicity, an extremely detailed sub-classification is avoided: anatomical variations of uterine, cervical and vaginal anomalies are grouped in subclasses having as criterion the clinical significance of the abnormality.

\section{Definitions}

\section{Uterine main classes and sub-classes}

- Class UO incorporates all cases with normal uterus. A normal uterus is any uterus having either straight or curved interostial line but with an internal indentation at the fundal midline not exceeding $50 \%$ of the uterine wall thickness. The use of absolute numbers (e.g. indentation of $5 \mathrm{~mm}$ ) is avoided in definitions as uterine dimensions as well as uterine wall thickness could normally vary from one patient to another. Thus, it was decided to define uterine deformity as proportions of uterine anatomical landmarks (e.g. uterine wall thickness). The addition of normal uterus gives the opportunity to independently classify congenital malformations of the cervix and vagina [16, 25, 27].

- Class U1 or Dysmorphic uterus incorporates all cases with normal uterine outline but with an abnormal shape of the uterine cavity excluding septa. Class I is further subdivided into three categories;

- Class Ula or T-shaped uterus characterized by a narrow uterine cavity due to thickened lateral walls with a correlation $2 / 3$ uterine corpus and 1/3 cervix,

- Class U1b or uterus infantilis characterized also by a narrow uterine cavity without lateral wall thickening and an inverse correlation of $1 / 3$ uterine body and $2 / 3$ cervix

- Class U1c or others which is added to include all minor deformities of the uterine cavity including those with an inner indentation at the fundal midline level of less than $50 \%$ of the uterine wall thickness. This aims to facilitate groups who want to study patients with minor deformities and to clearly differentiate them from patients with septate uterus [12, 29]. Usually, dysmorphic uteri are smaller in size.

- Class U2 or septate uterus incorporates all cases with normal fusion and abnormal absorption of the midline septum. Septate is defined as the uterus with normal outline and an internal indentation at the fundal midline exceeding $50 \%$ of the uterine wall thickness. This indentation is characterized as septum and it could divides partly or completely the uterine cavity including in some cases cervix and/or vagina (see cervical and vaginal anomalies). 


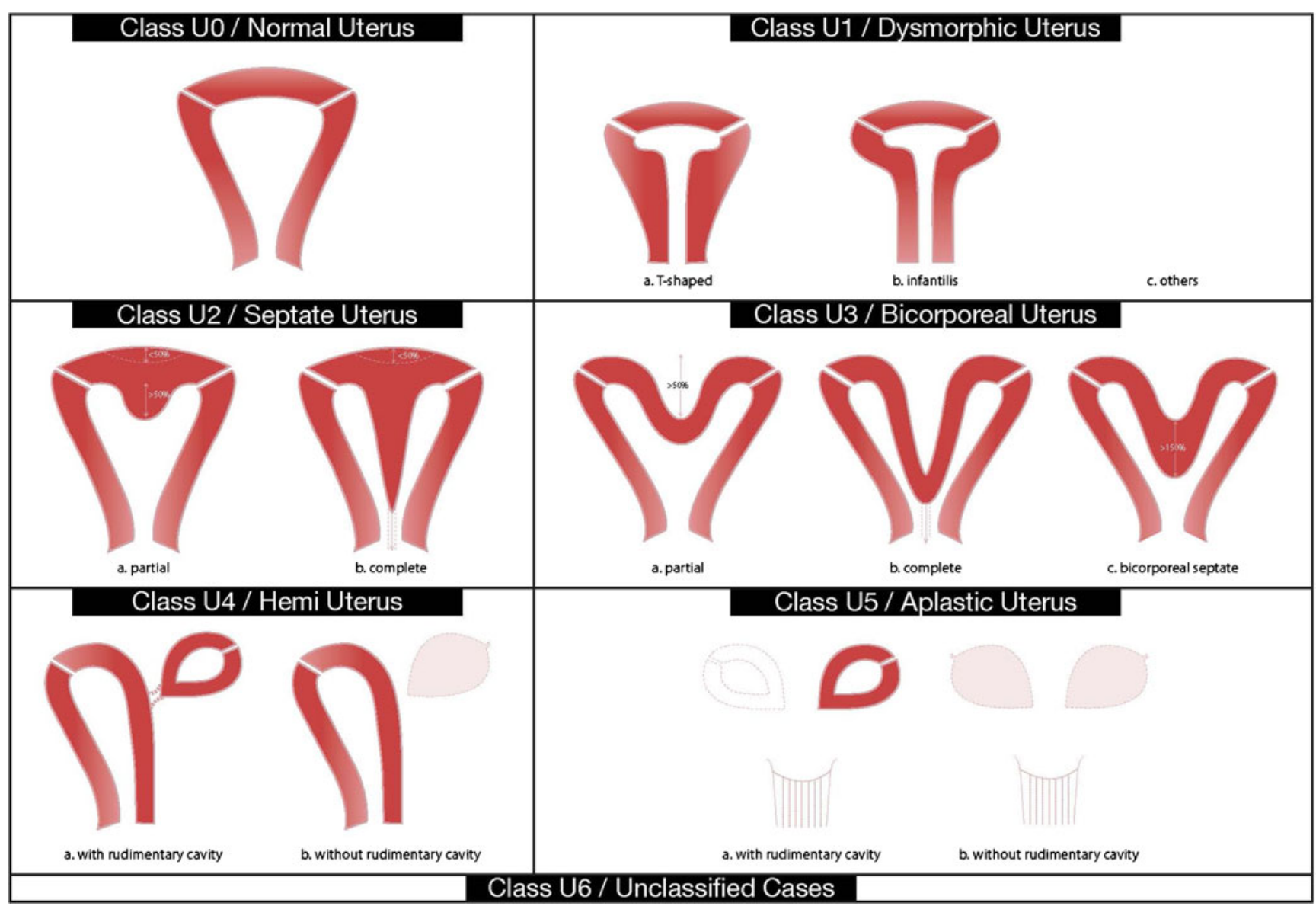

Fig. 2 ESHRE/ESGE classification of uterine anomalies: schematic representation (Class U2: internal indentation $>50 \%$ of the uterine wall thickness \& external contour straight or with indentation $<50 \%$, Class
U3: external indentation $>50 \%$ of the uterine wall thickness, Class $\mathrm{U} 3 \mathrm{~b}$ : width of the fundal indentation at the midline $>150 \%$ of the uterine wall thickness)
Class U2 is further divided into two sub-classes according to the degree of the uterine corpus deformity:

- Class U2a or partial septate uterus characterized by the existence of a septum dividing partly the uterine cavity above the level of the internal cervical os

- Class U2b or complete septate uterus characterized by the existence of a septum fully dividing the uterine cavity up to the level of the internal cervical os. Patients with complete septate uterus (class U2b) could have or not cervical (e.g. bicervical septate uterus) and/or vaginal defects (see cervical/vaginal anomalies) [14].

- Class U3 or bicorporeal uterus incorporates all cases of fusion defects. As bicorporeal is defined the uterus with an abnormal fundal outline; it is characterized by the presence of an external indentation at the fundal midline exceeding $50 \%$ of the uterine wall thickness. This indentation could divide partly or completely the uterine corpus including in some cases the cervix and/or vagina (see cervical and vaginal anomalies). As it could easily be imagined, it is also associated with an inner indentation at the midline level that divides the cavity as happens also in case of septate uterus.

Class U3 is further divided into three subclasses according to the degree of the uterine corpus deformity:

- Class U3a or partial bicorporeal uterus characterized by an external fundal indentation partly dividing the uterine corpus above the level of the cervix,

- Class U3b or complete bicorporeal uterus characterized by an external fundal indentation completely dividing the uterine corpus up to the level of the cervix

- Class U3c or bicorporeal septate uterus characterized by the presence of an absorption defect in addition to the main fusion defect. In patients with bicorporeal septate uterus (class U3c) the width of the midline fundal indentation exceeds by $50 \%$ the uterine wall thickness; these patients could be partially treated by hysteroscopic cross section of the septate element of the defect. It should be noted, also, that patients with complete bicorporeal uterus (class U3b) could 


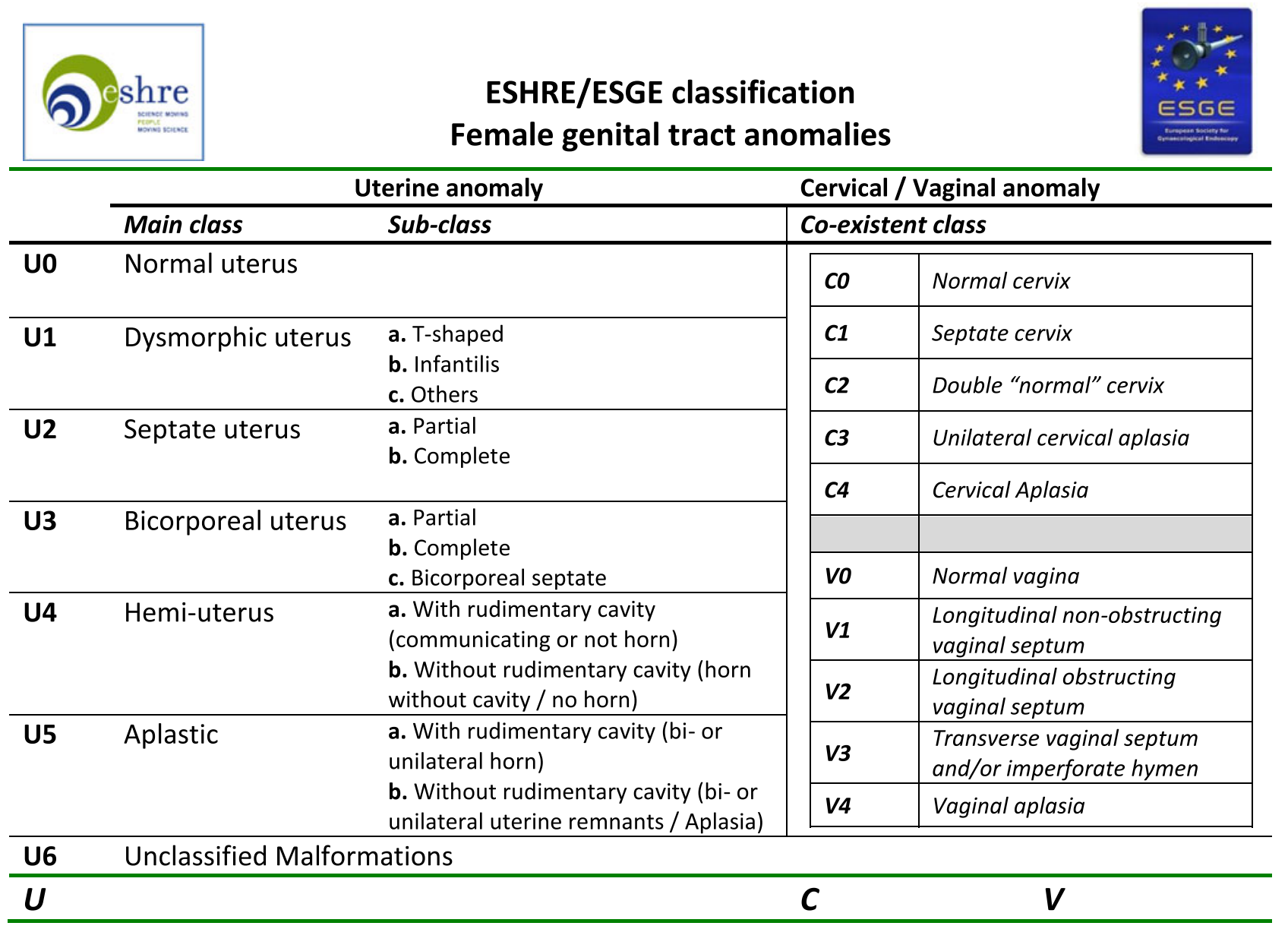

\section{Associated anomalies of non-Müllerian origin:}

\section{Drawing of the anomaly}

Fig. 3 Scheme for the classification of female genital tract anomalies according to the new ESHRE/ESGE classification system 
have or not co-existent cervical (e.g. double cervix/formerly Didelphys uterus) and/or vaginal defects (e.g. obstructing or not vaginal septum).

- Class U4 or hemi-uterus incorporates all cases of unilateral formed uterus. Hemi-uterus is defined as the unilateral uterine development; the contralateral part could be either incompletely formed or absent. It is a formation defect; the necessity to classify it in a different class than that of aplastic uterus (formation defect) is due to the existence of a fully developed functional uterine hemicavity.

Class U4 is further divided into two sub-classes depending on the presence or not of a functional rudimentary cavity;

- Class U4a or hemi-uterus with a rudimentary (functional) cavity characterized by the presence of a communicating or non-communicating functional contralateral horn

- Class U4b or hemi-uterus without rudimentary (functional) cavity characterized either by the presence of non-functional contralateral uterine horn or by aplasia of the contralateral part. The presence of a functional cavity in the contralateral part is the only clinically important factor for complications, such as hematocavity or ectopic pregnancy in the rudimentary horn or hemato-cavity and treatment (laparoscopic removal) is always recommended even if the horn is communicating $[10,28]$.

- Class U5 or aplastic uterus incorporates all cases of uterine aplasia [4, 22]. It is a formation defect characterized by the absence of any fully or unilaterally developed uterine cavity. However, in some cases there could be bior unilateral rudimentary horns with cavity, while in others there could be uterine remnants without cavity [22]. Treatment options in patients having rudimentary horn with cavity are not yet clear [23]. Furthermore, it should be noted that patients with aplastic uterus could usually have co-existent defects (e.g. vaginal aplasia/MayerRokitansky-Küster-Hauser syndrome) [22]

Class U5 is further divided into two sub-classes depending on the presence or not of a functional cavity in an existent rudimentary horn;

- Class U5a or aplastic uterus with rudimentary (functional) cavity characterized by the presence of bi- or unilateral functional horn,

- Class U5b or aplastic uterus without rudimentary (functional) cavity characterized either by the presence of uterine remnants or by full uterine aplasia. The presence of a horn with cavity is clinically important, and it is used as a criterion for sub-classification because it is combined with health problems (cyclic pain and/or hemato-cavity) necessitating treatment.
- Class U6 is kept for still unclassified cases. Modern imaging technology (ultrasound and /or magnetic resonance imaging) could provide objective estimations of uterine anatomy for the needs of differential diagnosis among the six groups. However, infrequent anomalies, subtle changes or combined pathologies could not be allocated correctly to one of the six groups. A sixth class was created for these cases in order to keep the other groups "clear". Furthermore, the system is designed to include, hopefully, all cases resulting from formation, fusion or absorption defects of normal embryological development. Duplication defects or ectopic Müllerian tissue anomalies, if existing, could not be described; these anomalies could be put in this class.

\section{Co-existent cervical anomalies}

- Sub-class C0 or normal cervix incorporates all cases of normal cervical development.

- Sub-class C1 or septate cervix incorporates all cases of cervical absorption defects. It is characterized by the presence of a normal externally rounded cervix with the presence of a septum.

- Sub-class C2 or double cervix incorporates all cases of cervical fusion defects. It is characterized by the presence of two distinct externally rounded cervices; these two cervices could be either fully divided or partially fused. It could be combined with a complete bicorporeal uterus as a class $\mathrm{U} 3 \mathrm{~b} / \mathrm{C} 2$ in the formerly Didelphys uterus.

- Sub-class C3 or unilateral cervical aplasia incorporates all cases of unilateral cervical formation. It is characterized by the unilateral, only, cervical development; the contralateral part could be either incompletely formed or absent. Obviously, this has happened in class U4 patients; however, this is not necessary to be mentioned in the final classification report (class U4 instead of class $\mathrm{U} 4 / \mathrm{C} 3$ ) as being apparent. On the other hand, this subclass gives the opportunity to classify other seldom anomalies such as complete bicorporeal uterus with unilateral cervical aplasia as class $\mathrm{U} 3 \mathrm{~b} / \mathrm{C} 3$, which is a severe obstructing anomaly.

- Sub-class C4 or cervical aplasia incorporates all cases of complete cervical aplasia but also those of severe cervical formation defects. It is characterized either by the absolute absence of any cervical tissue or by the presence of severely defected cervical tissue such as cervical cord, cervical obstruction and cervical fragmentation. The decision to include all variants of cervical dysgenesis in subclass C4 was made in order to avoid an extremely extensive sub-classification, which does not seem to be user friendly. This sub-class could be combined with a normal or a defected uterine body and gives the opportunity to classify all obstructing anomalies due to cervical defects. 


\section{Co-existent vaginal anomalies}

- Sub-class V0 or normal vagina incorporates all cases of normal vaginal development.

- Sub-class V1 or longitudinal non-obstructing vaginal septum. The incorporated anomaly in this sub-class is clear; it gives the opportunity to classify variants of septate or bicorporeal uteri together with septate or double cervices.

- Sub-class V2 or longitudinal obstructing vaginal septum. The incorporated anomaly in this sub-class is also clear, and its utility for the effective classification of obstructing anomalies due to vaginal defects is obvious.

- Sub-class V3 or transverse vaginal septum and/or imperforate hymen. This sub-class incorporates obviously different vaginal anomalies and their variants (mainly those of transverse vaginal septa); this was decided in order to avoid an extremely extensive sub-classification for the classification system's simplicity. The decision to put together those vaginal anomalies in this sub-class is due to the fact that they are usually present as isolated vaginal defects and they have the same clinical presentation (obstructing anomalies).

- Sub-class V4 or vaginal aplasia incorporates all cases of complete or partial vaginal aplasia.

\section{Concluding remarks}

The CONUTA ESHRE/ESGE Working Group for the study of congenital malformations of the female genital tract presents the new ESHRE/ESGE classification system. The development of the system was based on the scientific work of critical review of the advantages and disadvantages of current proposals on the use of the DELPHI procedure for consensus assessment among the scientists working in this field and on consensus development by the Scientific Committee of this project. The use of the DELPHI procedure gave the opportunity to a large number of scientists to participate. Almost 90 participants took part in the process of development of the new classification system, contributing with their structured answers and comments. A new clinical approach for the classification of uterine anomalies is proposed.

Uterine anatomy is the basis of the new system. Embryological origin has been adopted as the secondary basic characteristic in the design of the main classes. Cervical and vaginal anomalies are classified in independent co-existent sub-classes. It seems that the new system fulfils the needs and expectations of a large group of experts in the field. Clinicians could use Fig. 3 for an easy and precise description of anomalies, and they could also draw the scheme of the malformation. The ESHRE/ESGE classification system of female genital anomalies could also be used as a starting point for the development of guidelines for their diagnosis and treatment.

Acknowledgments The CONUTA group would like to thank the ESHRE and ESGE central offices and executives for their support, P. Westerlinck for his support in the running of DELPHI procedure and the graphic designer B. De Leva for the drawings. All members of the expert panel for their generous contribution of their views and time: Adnan B (UK), Alatas C (TR), Albu DN (RO), Al-Turki H (SA), Athanasiadis A (GR), Bartkowiak R (PL), Beja Osorio F (PT), Benmachiche A (FR), Bogdan D (RO), Bosteels J (BE), Brollman H (NL), Canis M (FR), Carvalho JLS (PT), Casadio P (IT), Catalin-Radu M (RO), Chatzipapas J (GR), Conti Ribeiro S (BR), Creatsas G (GR), Creighon S (UK), Dekker JJML (NL), de Souza Van Nimwegen AM (BR), Donnez J (BE), Duräo M (PT), El-Kehdy G (LB), Esposito A (IT), Exacoustos C (IT), Farrugia M (UK), Fernandez H (FR), Franchini M (IT), Gambadauro P (SW), Nikolopoulos G (UK), Ghi T (IT), Giuliani A (AT), Gomel V (CA), Gordts S (BE), Gubbini G (IT), Hall-Craggs M (UK), Heinonen P (FI), Kavallaris A (GR), Khalaf Y (UK), Klyucharov I (RU), La Prea C (VE), Langebrekke A (NL), Lavery SA (UK), Leone F (IT), Loutradis D (GR), Lyra M (BR), Luthra A (IN), Makedos A (GR), Marques C (PT), Molinas R (PY), Mollo F (IT), Molnar BG (HU), Mueller M (CH), Neuberg M (PO), Nisolle M (BE), Ntailianas S (GR), Nytun O (NO), Ogutu D (UK), Oppelt P (AT), Pabuccu R (TR), Pados G (GR), Papadopoulos N (GR), Paschopoulos M (GR), Pinto Coutinho SP (PT), Radwan M (PL), Raine Fenning N (UK), Reljic M (SLO), Ribic-Pucelj M (SLO), Ruhlmann C (AR), Salim BA (LB), Saridogan E (UK), Schettini SCA (IT), Razvan S (RO), Chouliaras S (UK), Sredanovic D (SLO), Theodoridis T (GR), Tica V (RO), Torok P (HU), Tsakos I (GR), Turan H (TR), Van Holsbeke C (BE), Verguts J (BE), Vidakovic S (SE), and Zegura B (SLO).

Authors' roles Scientific coordinators: G.G. and R.C.; Delphi procedure: S.G. (running) and H.B. (quality control); ESHRE: L.G. (Executive Commitee) and V.T. (Special Interest Group of Reproductive Surgery); ESGE: S.B. (Executive Committee) and S.G. (Special Interest Group of Reproductive Surgery); Scientific Committee: S.B., R.C., C.D., A.D., S.G., M.G., G.G., T.-C.L. and V.T.; All the authors contributed to the review of the manuscript.

\section{Conflict of interest None}

Funding This project was supported financially by both ESHRE and ESGE.

Open Access This article is distributed under the terms of the Creative Commons Attribution License which permits any use, distribution, and reproduction in any medium, provided the original author(s) and the source are credited.

\section{Reference}

1. Acien P, Acien M, Sanchez-Ferrer M (2004) Complex malformations of the female genital tract. New types and revision of classification. Hum Reprod 19:2377-2384

2. Acien P, Acien MI (2011) The history of female genital tract malformation classifications and proposal of an updated system. Hum Reprod Update 17:693-705

3. American Fertility Society (1988) The AFS classification of adnexal adhesions, distal tubal occlusion, tubal occlusion secondary 
to tubal ligation, tubal pregnancies, Mullerian anomalies and intrauterine adhesions. Fertil Steril 49:944-955

4. Aittomaki K, Eroila H, Kajanoja P (2001) A population-based study of the incidence of Müllerian aplasia in Finland. Fertil Steril 76:624-625

5. Brucker SY, Rall K, Campo R, Oppelt P, Isaacson K (2011) Treatment of congenital malformations. Semin Reprod Med 29:101-112

6. Buttram VC, Gibbons WE (1979) Mullerian anomalies: a proposed classification (an analysis of 144 cases). Fertil Steril 32:40-46

7. Chan YY, Jayaprakasan K, Zamora J, Thornton JG, Raine-Fenning N, Coomarasamy A (2011) The prevalence of congenital uterine anomalies in unselected and high-risk populations: a systematic review. Hum Reprod Update 17:761-771

8. Chan YY, Jayarpakasan K, Tan A, Thornton JG, Coomarasamy A, Raine-Fenning NJ (2011) Reproductive outcomes in women with congenital uterine anomalies: a systematic review. Ultrasound Obstet Gynecol 38:371-382

9. El Saman AM, Shahin AY, Nasr A, Tawfik NA, Saadeldeen HS, Othman ER, Habib DM, Abdel-Aleem MA (2012) Hybrid septate uterus, coexistence of bicornuate and septate varieties: a genuine report. J Obstet Gynaecol Res 38:1308-1314

10. Fedele L, Bianchi S, Zanconato G, Berlanda N, Bergamini V (2005) Laparoscopic removal of the cavitated noncommunicating rudimentary uterine horn: surgical aspects in 10 cases. Fertil Steril 83:432-436

11. Fink A, Kosecoff J, Chassin M, Brook RH (1984) Consensus methods: characteristics and guidelines for use. Am J Public Health 74:979-983

12. Gergolet M, Campo R, Verdenik I, Kenda Suster N, Gordts S, Gianaroli L (2012) No clinical relevance of the height of fundal indentation in subseptate or arcuate uterus: a prospective study. RBM Online 24:576-582

13. Grimbizis GF, Camus M, Tarlatzis BC, Bontis JN, Devroey P (2001) Clinical implications of uterine malformations and hysteroscopic treatment results. Hum Reprod Update 7:161-164

14. Grimbizis GF, Campo R (2010) Congenital malformations of the female genital tract: the need for a new classification system. Fertil Steril 94:401-407

15. Grimbizis GF, Campo R, on behalf of the SC of the CONUTA ESHRE/ ESGE working group:, Gordts G, Brucker S, Gergolet M, Tanos V, Li T-C, De Angelis C, Di Spiezio SA (2012) Clinical approach for the classification of congenital uterine malformations. Gynecol Surg 9:119-129

16. Grimbizis GF, Tsalikis T, Mikos T, Papadopoulos N, Tarlatzis BC, Bontis JN (2004) Successful end-to-end cervico-cervical anastomosis in a patient with congenital cervical fragmentation: case report. Hum Reprod 19:1204-1210

17. Gubbini G, Di Spiezio SA, Nascetti D, Marra E, Spinelli M, Greco E, Casadio P, Nappi C (2009) New outpatient subclassification system for American Fertility Society classes V and VI uterine anomalies. J Min Invas Gynecol 16:554-561
18. Joki-Erkkilä MM, Heinonen PK (2003) Presenting and long-term clinical implications and fecundity in females with obstructing vaginal malformations. J Pediatr Adolesc Gynecol 16:307-312

19. Jones J, Hunter D (1995) Consensus methods for medical and health services research. BMJ 311:376-380

20. Mollo A, De Franciscis P, Colacurci N, Cobellis L, Perino A, Venezia R, Alviggi C, De Placido G (2009) Hysteroscopic resection of the septum improves the pregnancy rate of women with unexplained infertility: a prospective controlled trial. Fertil Steril 91:2628-2631

21. Oppelt P, Renner SP, Brucker S, Strissel PL, Strick R, Oppelt PG, Doerr HG, Schott GE, Hucke J, Wallwiener D, Beckmann MW (2005) The VCUAM (Vagina Cervix Uterus Adnex Associated Malformation) Classification: a new classification for genital malformations. Fertil Steril 84:1493-1497

22. Oppelt PG, Lermann J, Strick R, Dittrich R, Strissel P, Rettig I, Schulze C, Renner SP, Beckmann MW, Brucker S, Katharina Rall K, Mueller A (2012) Malformations in a cohort of 284 women with Mayer-Rokitansky-Ku ster-Hauser syndrome (MRKH). Reprod Biol Endocrinol 10:57-64

23. Rall K, Barresi G, Wallwiener D, Brucker SY, Staebler A (2013) Uterine rudiments in patients with Mayer-Rokitansky-Ku sterHauser syndrome consist of typical uterine tissue types with predominantly basalis-like endometrium. Fertil Steril 99(5):1392-9

24. Rock JA, Carpenter SE, Wheeless CR, Jones HWJ (1995) The clinical management of maldevelopment of the uterine cervix. $\mathrm{J}$ Pelv Surg 1:129-133

25. Rock JA, Roberts CP, Jones HW (2010) Congenital anomalies of the uterine cervix: lessons from 30 cases managed clinically by a common protocol. Fertil Steril 94:1858-1863

26. Saravelos SH, Cocksedge KA, Li T-C (2008) Prevalence and diagnosis of congenital uterine anomalies in women with reproductive failure: a critical appraisal. Hum Reprod Update $14: 415-419$

27. Strawbrigde LC, Crough NS, Cutner AS, Creighton SM (2007) Obstructive Mullerian anomalies and modern laparoscopic management. J Pediatr Adolesc Gynecol 20:195-200

28. Theodoridis TD, Saravelos H, Chatzigeorgiou KN, Zepiridis L, Grimbizis GF, Vavilis D, Loufopoulos A, Bontis JN (2006) Laparoscopic management of unicornuate uterus with non-communicating rudimentary horn (three cases). RBM Online 12:126-128

29. Tomazevic T, Ban-Frangez H, Ribic-Pucelj M, Premru-Srsen T, Verderik I (2007) Small uterine septum is an important risk variable for preterm birth. Eur J Obstet Gynecol Reprod Biol 135:154157

30. Troiano RN, McCarthy SM (2004) Müllerian duct anomalies: imaging and clinical issues. Radiology 233:19-34

31. Vonk Noordegraaf A, Huirne J, Brölmann H, van Mechelen W, Anema J (2011) Multidisciplinary convalescence recommendations after gynaecological surgery: a modified Delphi method among experts. BJOG 118:1557-1567 